\title{
LA SENSIBILIZACIÓN CULTURAL EN LAS CLASES DE INGLÉS DE LA UNIVERSIDAD METROPOLITANA DEL ECUADOR
}

Lic. Verónica Fajardo Blanco.

Docente de inglés

Universidad Metropolitana del Ecuador.

vfajardo@umet.edu.ec

Palabras claves: cultura, sensibilización cultural, tecnología en la educación, enseñanza de idiomas.

Keywords: culture, cultural awareness, education technology, language teaching
Recibido: 04 de julio de 2016

Aceptado: 19 de agosto de 2016

\section{RESUMEN}

Actualmente, el involucrar la sensibilización cultural en la enseñanza de los idiomas ha cobrado una importancia significativa. Los estudiantes están expuestos continuamente a expresiones culturales provenientes de casi cualquier lugar del planeta. La globalización ha logrado que el acceso a la información sea prácticamente inmediato. Por lo tanto, acercarse a la enseñanza de idiomas desde un método convencional, no contextualizado, o culturalmente insensible, traería falta de motivación y, en última instancia, resultados no satisfactorios en el aprendizaje de la lengua extranjera. En este trabajo se presenta la experiencia de la incorporación de la sensibilización cultural en la enseñanza del inglés como lengua extranjera a estudiantes de todas las carreras en la Universidad Metropolitana del Ecuador. La inclusión de elementos culturales auténticos en la planificación de las clases y la promoción de la generación de contenidos culturales por parte de los estudiantes de idiomas ha sido una experiencia de enseñanza memorable en el departamento de idiomas UMET.

\section{ABSTRACT}

Students are continuously exposed to cultural outputs from almost anywhere on the planet. Globalization made access to information almost immediate. Therefore, approaching the teaching of languages with a conventional, non- contextualized, culturally insensitive method, would bring lack of motivation, and, ultimately, poor results in the learning of the foreign language. This paper presents the experience of including cultural awareness in the teaching of English as a foreign language to students of all majors at Universidad Metropolitana del Ecuador. The inclusion of authentic cultural inputs in the lesson planning and promoting the production of cultural outputs by the language students has been a remarkable teaching experience at the UMET language department. 


\section{INTRODUCCIÓN}

La necesidad imperiosa de aprender una lengua extranjera se hace cada día más evidente. Ser parte de la llamada aldea global, con toda su diversidad, no impide comprender la ventaja comunicativa que representa hablar un nuevo idioma. Ser capaces de comunicarse en una lengua extranjera ofrece no sólo el acceso a nueva información, sino también una nueva perspectiva para entender y utilizar esa información.

Según Lange (2003), la comprensión de las perspectivas, es decir, los significados, las actitudes, los valores y las ideas de las culturas estudiadas, es el objetivo final para los alumnos de las lenguas extranjeras.

Como consecuencia, ser conscientes de la cultura que rodea el idioma que se aprende se convierte en un elemento inherente del proceso de aprendizaje. Además, esta no es sólo un vehículo para llegar a la adquisición completa de la lengua extranjera, sino que está en el centro mismo del proceso de aprendizaje. En última instancia, se convierte en la razón del aprendizaje de idiomas.

Los estudiantes pueden entender mejor un idioma y obtener todas las habilidades comunicativas al ser expuestos a los elementos culturales que rodean este idioma. Sin embargo, al mismo tiempo, utilizan su conocimiento de la lengua para comprender a la cultura misma y a los hablantes nativos de esta lengua.

Estas ideas se presentan como reveladoras y esperanzadoras. La posibilidad de ver el aprendizaje de idiomas no sólo como un proceso cognitivo, sino también como un puente entre las culturas puede reivindicar el papel que tiene el profesor de lenguas en la sociedad actual. Bajo este enfoque, los docentes se convierten en promotores de una manera más abierta, tolerante y optimista de ver el mundo.

Según Rodríguez (2011), la sensibilización cultural reconoce que todos somos moldeados por nuestro entorno cultural, lo que influye en la manera en que interpretamos el mundo que nos rodea, y que nos percibimos a nosotros mismos y nos relacionamos con otras personas (...), la sensibilización cultural implica la capacidad de hacer a un lado lo que la gente piensa, y tomar conciencia de sus valores culturales, creencias y percepciones.

Por ende, ser consciente de las diferencias entre la propia cultura y la cultura relacionada con la lengua extranjera proporciona a los estudiantes la habilidad de comunicación asertivas. Es decir, estos adquieren la capacidad de percibir intenciones, entender vocabulario y de procesar información en el idioma extranjero con mayor facilidad y, como consecuencia, se acercan a la posibilidad de producir frases con un lenguaje apropiado a cada situación.

Para que el docente sea capaz de ayudar a los estudiantes a alcanzar esto, tiene que tomar en cuenta los elementos culturales que rodean al estudiante y también los que se relacionan a la lengua que está siendo estudiada. Aunque es necesario que no exista absolutamente ningún prejuicio al acercarse a los estudiantes, el profesor debe en todo momento tener en cuenta las características culturales de los alumnos, así como las de la lengua extranjera, con el fin de abordar cada situación correctamente.

Por tanto, podríamos decir que la enseñanza en Copenhague será completamente diferente a la enseñanza en Quito; y el maestro siempre estará al tanto de este hecho. 
Y precisamente este documento se refiere a una experiencia que tuvo lugar en Quito, la capital de Ecuador.

Ser llamada "la ciudad de la mitad del mundo" se convierte en una metáfora de Quito. El constante flujo de inmigrantes hacia este país latinoamericano ha hecho a Ecuador un país colorido. La influencia de las diferentes lenguas y culturas extranjeras ha sido sumada a la convivencia previa de diferentes culturas nativas en Ecuador. Los movimientos migratorios de los últimos años han ayudado a que este territorio se convierta en una auténtica mezcla cultural.

En tales circunstancias, la necesidad de un enfoque cultural en la enseñanza de idiomas se vuelve esencial. Enseñar en un aula multiétnica, que es tan característica del país, exige una gestión responsable del sílabo, con la cual la sensibilización cultural esté en el núcleo del proceso de enseñanza.

Teniendo esto en mente, el profesor se convierte en responsable de la promoción y la difusión cultural en el aula, y esta promoción no es un elemento opcional, sino un aspecto clave en la planificación de las actividades.

Estas actividades se llevan a cabo en un ambiente donde la interacción entre el docente y el estudiante facilita un proceso a través del cual el alumno se convierte en receptor y emisor de contenidos. Estos contenidos están estrechamente relacionados con la experiencia del alumno, ya que una persona sólo puede hablar de lo que le es familiar. Como resultado, lo que el estudiante produce o crea siempre será una representación de su cultura en contenido y forma. Los elementos de su cultura, así como sus creencias, valores y costumbres tendrán un fuerte impacto en el proceso creativo.

Por consiguiente, el aula se convierte en el escenario perfecto para un intercambio cultural, ya que los estudiantes no sólo están expuestos a la cultura de la nueva lengua al acercarse a las creencias y costumbres que la rodean; sino que también tienen la posibilidad de crear nuevos contenidos culturales en el idioma extranjero, desde la perspectiva de su propia cultura.

Teniendo esto en cuenta, el profesor puede planificar una serie de actividades con el objetivo de aumentar la sensibilidad cultural en el estudiante.

Según Fleet (2006) estas son algunas de las estrategias a tener en cuenta en la planificación de actividades para fomentar la sensibilización cultural en el aula: Internet como recurso, materiales auténticos virtuales, presentación cultural, investigación y personalización de contenidos culturales.

En primer lugar, el uso de Internet como recurso proporciona al profesor material vigente que puede mostrar a los estudiantes las tradiciones y costumbres de la cultura extranjera. Además, es la manera más rápida para obtener acceso a contenidos culturales. Los materiales auténticos virtuales se refieren a la utilización de productos audiovisuales auténticos, grabados originalmente en el idioma extranjero. Estos proporcionan a los estudiantes una verdadera representación de la cultura. Presentación cultural se relaciona con las presentaciones orales de los aspectos específicos de la cultura extranjera. Esta estrategia ayuda a los estudiantes a mejorar su fluidez en el idioma extranjero.

La investigación es fundamental en todas las estrategias, ya que el profesor y los alumnos deben hacer una investigación estructurada de los temas que se presentarán. 
Es importante señalar que la investigación impide que el maestro haga uso de estereotipos para enseñar la cultura, lo que con el tiempo podría hacer daño. Por último, la personalización de los contenidos culturales permite a los estudiantes producir material y hablar libremente sobre sus propias características culturales.

Fue precisamente esta estrategia, la creación de contenido personalizado, la que fue usada en el aula con el fin de aumentar la sensibilización cultural.

\section{La producción de contenidos audiovisuales en inglés: una forma entretenida de aprender una lengua extranjera a través de la sensibilización cultural}

A partir de mayo de 2015, los estudiantes de inglés en la Universidad Metropolitana del Ecuador han producido videos hechos en casa como parte de su proceso de aprendizaje. Han creado proyectos audiovisuales cortos con el propósito de desarrollar habilidades comunicativas, reforzando al mismo tiempo la conciencia de su propia cultura.

Como preparación a estas tareas, los estudiantes están continuamente expuestos a vídeos relacionados con las culturas americana y británica. Tienen la oportunidad de ver videos y llevan a cabo actividades de comprensión acerca de las tradiciones de Inglaterra y los EE.UU... De igual forma, participan en discusiones acerca de las diferencias entre lo que pueden ver en los videos y lo que perciben como su propia cultura.

A mitad de semestre, los estudiantes comienzan a planificar sus propios contenidos culturales: los videos hechos en casa acerca de sus habilidades y talentos, así como informes sobre los elementos culturales del Ecuador, como la comida y la música populares.

En las siguientes imágenes, se pueden observar los trabajos audiovisuales de estudiantes de diferentes niveles de inglés de la Universidad Metropolitana del Ecuador:

En primer lugar, se puede ver a un estudiante de inglés del nivel 1, mientras habla frente a cámara acerca de los rasgos de su personalidad.

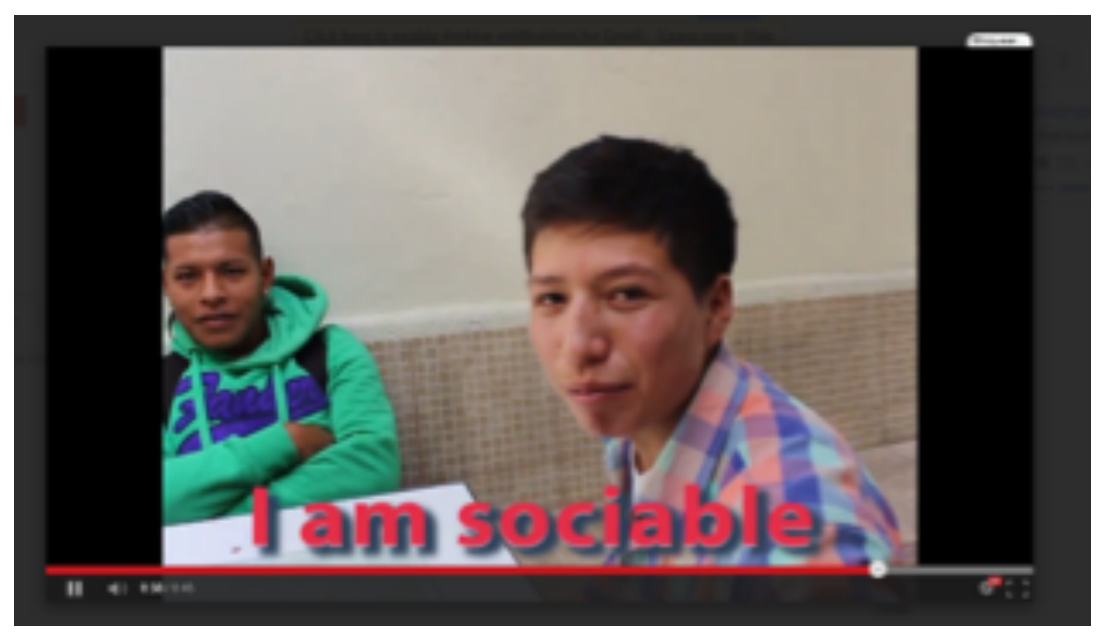


En segundo lugar, se observa a una estudiante de inglés del nivel 4, presentando una receta de cocina, con todos los pasos a seguir.

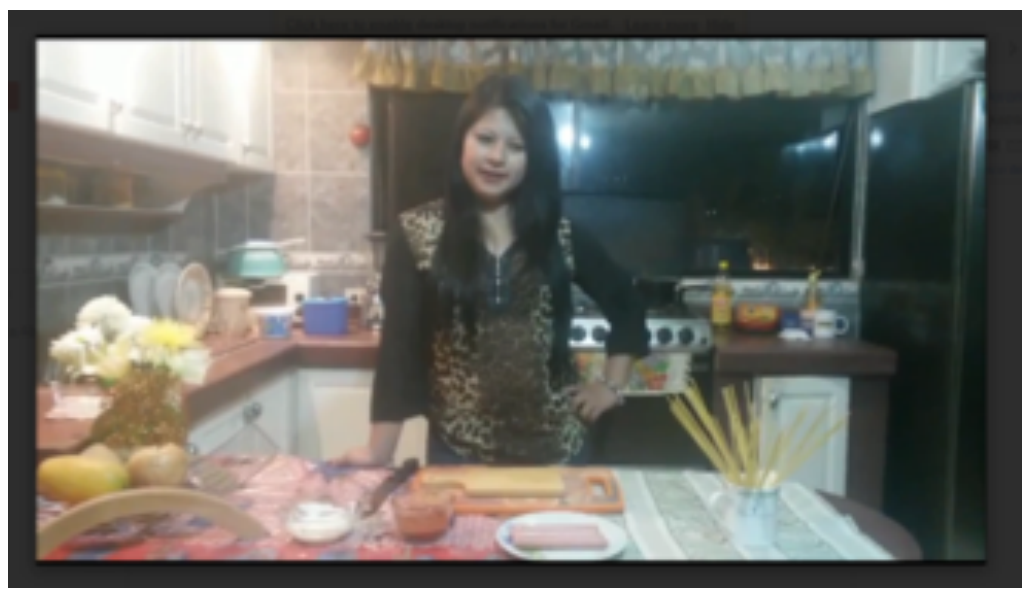

\section{CONCLUSIONES}

El planificar y liderar proyectos que promueven la sensibilización cultural en el aula ha ayudado a ser más consciente de este elemento en la enseñanza de idiomas. Se deja claro lo importante que es en el proceso de aprendizaje de lenguas extranjeras el estudio de la cultura. Ser capaz de incentivar la sensibilidad cultural ha ayudado a verla no sólo como parte de la enseñanza de idiomas, sino como el objetivo final de la misma.

De igual forma, se ha convertido en un elemento fundamental en la construcción de la autoestima de los estudiantes, ya que representa una parte vital de la educación en este siglo, así como un componente crucial de la construcción de una sociedad más tolerante y pacífica. 


\section{REFERENCIAS BIBLIOGRÁFICAS}

Fleet, M. (2006). The role of culture in second or foreign language teaching: Moving beyond the classroom experience. Recuperado de http://www.eric.ed.gov/PDFS/ED491716.pdf

Lange, D. (2003) Culture at the core. Perspectives on Culture in second language learning. University of Minnesota. US.

Rodriguez, D. (2011) Developing cultural awareness of English speaking contexts in third year students of the English Major at the University of Cienfuegos: A proposal of tasks. University of Cienfuegos. Cuba. 